\title{
Desulphurization of Petroleum Waste
}

\author{
Ranjini Kumari \\ India
}

\begin{abstract}
The present study aimed at the removal of sulphur from the petroleum waste. It is a carbonaceous solid derived from oil refinery coker units or other cracking processes. Its high heat and low ash content make it good fuel for power generation in coal fired boilers, but petroleum coke is high in sulphur and low in volatile content which pose some environmental and technical problems with its combustion. The removal of sulphur is a gigantic task that can be achieved through various methods. The microbial method is an efficient and cost effective alternative method to chemical and physical methods because of its low demand for energy and less generation of waste by product. Microorganism used for the reduction of sulphur from pet coke is thiobacillus ferrooxidans. According to study of short interval, results suggest that with higher concentration of bacterial culture leaches sulphur more efficiently.
\end{abstract}

Keywords: Thiobacillus ferrooxidans; petroleum coke; Desulphurization

\section{Introduction}

Petroleum coke is often abbreviated as pet coke. It is a carbonaceous solid derived from oil refinery coker units or other cracking processes. Its high heat and low ash content make it good fuel for power generation in coal fired boilers, but petroleum coke is high in sulphur and low in volatile content which pose some environmental and technical problems with its combustion [1]. It is also considered as low temperature coking product at $900^{\circ}-1200^{\circ} \mathrm{F}$, which is used as a refinery and commercial fuel, in the manufacture of electrodes, abrasives, artificial graphite, and calcium carbide and as a metallurgical fuel. In order to meet current North American emission standards some form of sulphur captures is required. The raw petroleum coke is derived from the distillation petroleum crude in delayed cokers. It is a hard brittle substance, shiny and oily in appearance, very rich in fixed carbon with very low ash content [2].

Petroleum coke is composed primarily of elemental carbon organised as a porous polycrystalline carbon matrix. The specific chemical composition of any batch of petroleum coke is determined by the composition of the feed stocks used in the coking process, which in turn are dependent upon the composition of crude oil and refinery processing from which the feed stock is derived [3] [4].

Coke produced from feed stocks high in asphaltenes will contain higher concentrations of sulphur and metals than cokes produced from high aromatic feed stocks. This is because asphaltenes contain disappropriate fraction of those heteroatoms. Most of the sulphur in coke exists as organic sulphur bound to the carbon matrix. Other forms of sulphur found in coke include sulphate and pyritic sulphur, but these rarely make up more than $0.02 \%$ of the total sulphur in coke. Metals mainly vanadium and nickel, occur as metal chelates or porphyrine in the asphaltene fraction [5] [6]. Some metals are intercalated in the coke structure and are not chemically bonded so they become part of the ash and particulates. Metal concentrate in coke normally increase upon calcining due to weight loss from evolution of volatile matter.

The need for low-sulphur coal has assumed major proportions. Shortages of other fossil fuels, restrictions on sulphur oxide emissions, and technical problems associated with the use of high-sulphur coals in newly proposed coal conversion processes are contributing to the crisis. Free sulphur as such does not occur in coal to any significant extent. Sulphur is present in coal in organically bound combinations, in inorganic compounds mainly as pyrite $\left(\mathrm{FeS}_{2}\right)$, and especially in weathered coals as gypsum $\left(\mathrm{CaSO}_{4} \cdot 2 \mathrm{H}_{2} 0\right)$ and as ferrous sulfate $\left(\mathrm{FeSO}_{4} .7 \mathrm{H}_{2} 0\right)$. Inorganic sulfates and sulfides, e.g. barite $\left(\mathrm{BaSO}_{4},\right)$ and sphalerite $(\mathrm{ZnS})$, [7] [8] which normally occur only in trace concentrations, may be present. The three forms of sulphur commonly measured in coal are sulfate, pyritic, and organic sulphur [9].

The sulphur content is always determined by burning a weighed amount of the sample in an excess of air or oxygen, absorbing the oxides of sulphur in a suitable solution and determining sulphur either gravimetrically or by titration [10]. The lower the sulphur content, the better the crude. High sulphur content requires more extensive refining procedures for the production of satisfactory products [11]. They also promote the corrosion of refinery equipments. High sulphur stocks are called "sour", particularly if sulphur is corrosive. Low sulphur stocks are called "sweet". There is no particular sulphur level which is recognised as a dividing line.

Sulphur is an important nutrient for organism, key constituent of certain amino acids, proteins and other biochemical. Plants satisfy their nutritional needs for assimilating simple mineral compounds from the environment. This mostly occurs as sulphate dissolved in soil water that is taken up by the roots, or as gaseous 
sulphur dioxide that is obtained absorbed by foliage in environments where the atmosphere is somewhat polluted with this gas. Animals obtain the sulphur they need by eating plants or other animals, and digesting and assimilating their organic forms of sulphur, which are then used to synthesise necessary sulphur containing biochemical. But on combustion of pet coke, sulphur gets released into the atmosphere and causes air pollution. Sulphur occurs as an integral part of some of the coke and it is not accessible for microbial attack. The removal of sulphur from coke while retaining its fuel values is most difficult. Sulphur released into atmosphere, combines with oxygen $(\mathrm{O})$ and produces sulphur dioxide $\left(\mathrm{SO}_{2}\right)$.

$\mathrm{SO}_{2}$ released into the atmosphere causes a wide variety of health and environmental impacts because of the way it reacts with other substances in the air e.g. acid rain, Acid Mine Drainage, Respiratory effects from gaseous $\mathrm{SO}_{2}$, Respiratory effects from sulphate particles, Visibility impairment, Plant and water Damage, Aesthetic Damages

The best way is to limit the amount of $\mathrm{SO}_{2}$ emissions released in the atmosphere. Several industries have added scrubbers to their smoke stakes to reduce the amount of $\mathrm{SO}_{2}$ dumped in the atmosphere they are specially designed catalytic converters which are used to ensure that the gases coming out from exhaust pipes of automobiles are rendered harmless. Several industries which use coal or coke as fuel have begun to wash the coal or coke before using it thereby reducing the amount of sulphur present in the atmosphere and consequently the amount of emissions. The usage of coke with low $\mathrm{S}$ content also reduces the environmental problems that are occurring due to the sulphur release.

\section{Material and methods}

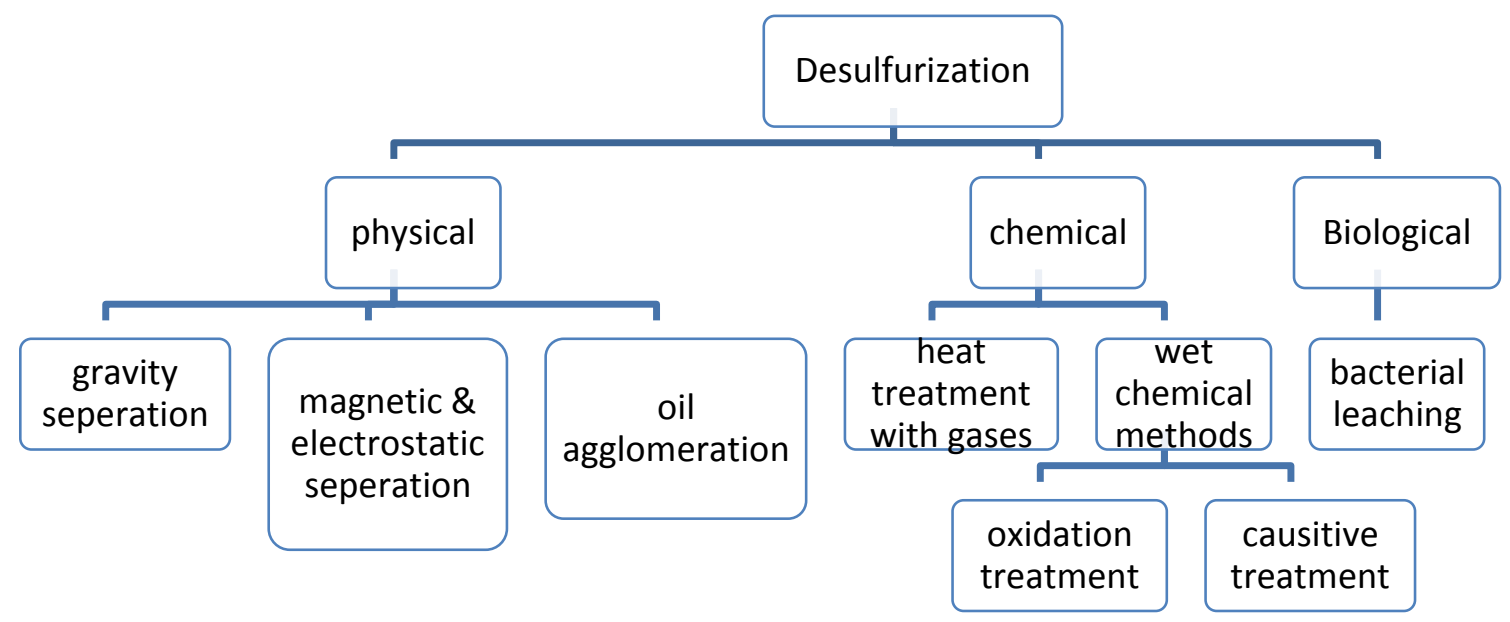

\section{1.Media Preparation Growth of microorganism:}

For the growth of Thiobacillus ferroxidans species ' $9 \mathrm{k}$ media' was used, having the following composition-

\begin{tabular}{|c|c|}
\hline Components & Quantity \\
\hline Ammonium Sulphate & 0.15 \\
\hline Potassium chloride & 0.05 \\
\hline Dipotassium Hydrogen Phosphate & 0.05 \\
\hline Magnesium Sulphate & 0.05 \\
\hline Calcium Nitrate & 0.01 \\
\hline pH & 2.5 \\
\hline Temperature & $37^{0} \mathrm{C}$ \\
\hline
\end{tabular}

\section{2.Procedure:}

For the growth of Thiobacillus species ' $9 \mathrm{k}$ media' was prepared. The bacteria were then inoculated into the media. Three experimental sets were employed:

1. One with pet coke sample $(1 \mathrm{gm}), 2 \mathrm{ml}$ of bacterial culture and $48 \mathrm{ml}$ of media

2. Second with same amount of sample, $10 \mathrm{ml}$ of culture and $90 \mathrm{ml}$ of media

3. Third with same amount of sample, $20 \mathrm{ml}$ of culture and $80 \mathrm{ml}$ of media.

The control set consists of $100 \mathrm{ml}$ of media along with sample $(1 \mathrm{gm})$. This set up was without bacterial culture. The experimental flasks were incubated at $37^{\prime}$ C.The incubated samples were drawn at regular interval of 1 
week. In the leached samples, the total sulfur was determined by following the Eshka's method.

\section{3.ESTIMATION OF SULPHUR}

Initially $1 \mathrm{gm}$ of sample was taken in crucible and $3 \mathrm{gm}$ of Eschka mixture was mixed into it. $1 \mathrm{gm}$ of eschka mixture was sprinkled over this sample so as to cover the entire sample. The crucible was then kept inside a muffle furnace at $800^{\circ} \mathrm{C}$ for $1.5 \mathrm{hrs}$. The crucible is then washed with hot distilled water to brush out the sample into a beaker. Around 4-5 washing (approx. 150 to 200) is done $15 \mathrm{ml}$ of concentrated $\mathrm{HCl}$ is then added to the beaker. The mixture was boiled for 5 minutes and was then filtered through 40 no. filter paper. The filter paper was washed with hot distilled water to make it acid free. To check for acid blue litmus paper can be used. The flilterate was then boiled to reduce it to up to $300 \mathrm{ml}$. To the mixture, $10 \mathrm{ml}$ of $\mathrm{BaCl} 2$ was added during boiling and the solution was incubated at room temperature for overnight. Some amount of precipitate is observed. This mixture is now filtered through filter paper no.42.the filter paper was washed with hot distilled water to make it chloride free. A free drops of $\mathrm{AgNO}_{3}$ (silver nitrate) is added to a test tube and 4-5 drops of the filtrate is added to it. This is done to check whether the solution has become chloride free the mixture is washed with hot distilled water until the silver nitrate solution in the test tube becomes transparent. This ensures the solution to be chloride free. The precipitate along with the filter paper was kept in a crucible and burnt in a muffle furnace at $800^{\prime} \mathrm{C}$ for 15 minutes. When the crucible gets cooled to some extent, weigh the crucible and note down the weight.

The total sulfur in the sample was calculated using the following formula:

$$
\% \mathrm{~S}=(\mathrm{X} * 0.1373 * 100) / \text { wt of the sample }
$$

Where, $\mathrm{X}$ (wt. of BaSO4 precipitate $)=($ wt. of crucible + residue $)$ - (wt. of empty crucible $)$

\section{Result And Discussion}

On the basis of the studies it is observed that desulfurization with thiobacillus ferrooxidans is a time taking process, so for better results, this process should be studied for long duration, since the bacterial concentration increases simultaneously with time. It is a general trend that there will be a sharp decline in the sulphur content of pet coke, but the results obtained from the study of two months of biodesulfurization does not show a significant decline in the sulphur content of pet coke. These results have not been found to show any significant relation along the time gradient. The decline in sulphur content can be attributed to the activity of thiobacillus ferrooxidans and its dependency on sulphur.

The other studies regarding biodesulfurization, which are carried out for over a long period, had reported a noticeable decline in the sulphur content of pet coke, both with increasing concentrations and increasing time intervals.

\section{Conclusion}

This process has been carried out only for 4 weeks so finally we cannot conclude anything but according to the data we have got during this short interval suggests that with higher concentration of bacterial culture the microorganism Thiobacillus ferrooxidans has leached sulphur more efficiently. At this point it cannot be said that why is there such variations, as it has been performed for very short duration. This process should be introduced at pilot scale so that this microbial leaching process may show immense field work with bacterial culture. This biodesulphurization process also helps us to keep the environment clean and pollution free. This will be very efficient and cost effective process than chemical and physical process, so that this process should be at large scale in mines or refineries which would produce refinery products of low sulphur content such as petroleum coke.

\section{References}

[1] IUPAC, Compendium of Chemical Terminology, 2nd ed. (the "Gold Book") (1997). Online corrected version: (2006-) "petroleum coke".

[2] Schoolbook, Chemistry 2000, Helge Mygind, ISBN 8755909922

[3] Al-Haj-Ibrahim, H. and B.I. Morsi. 1992. Desulfurization of Petroleum Coke: A Review. Ind. Eng. Chem. Res., 321:1835-1840.

[4] Al-Haj-Ibrahim, H. and M. M. Ali. 2005. Effect of the removal of sulphur and volatile matter on the true density of petroleum coke. Periodica polytechnica ser. Chem. Eng., 49(1):19-24.

[5] Ellis, P.J. and C.A. Paul. 2000a. Tutorial: Petroleum coke calcining and uses of calcined petroleum coke. Presented at the March 59, 2000, AIChE 2000 Spring National Meeting, Atlanta, GA.

[6] Ellis, P.J. and C.A. Paul. 2000b. Tutorial: Delayed coking fundamentals. Presented at the March 5-9, 2000, AIChE 2000 Spring National Meeting, Atlanta, GA.

[7] R. R. Ruch, H. J. Gluskoter, and N. F. Shimp, Illinois Geol. Survey 1Environmental Geology Note 72 (1974)

[8] H. J. Gluskoter and P. C. Lindahl, Science pg - 181, 264 (1973).

[9] Determination of Forms of Sulphur in Coal by N. F. Shimp, R. J. Helfinstine, and J. K. Kuhn (Illinois State Geological Survey, Urbana, I L 61801) pg - 99.

[10] Van Der Have, et. al. 1957

[11] Winslow (1955) 